\title{
Haemodynamic responses to laryngo- scopy and tracheal intubation in geriatric patients: effects of fentanyl, lidocaine and thiopentone
}

The haemodynamic responses to laryngoscopy and intubation after induction of anaesthesia with thiopensone alone or in combination with $1.5 \mathrm{mg} \cdot \mathrm{kg}^{-1}$ lidocaine andlor 1.5 or 3.0 $\mu \mathrm{g} \cdot \mathrm{kg}^{-1}$ fentanyl were measured in 150 patients over 64 years of age to determine whether lidocaine, fentanyl or both lidocaine and fentanyl attenuated the pressor response. Fentanyl reduced the rises in systolic, diastolic and mean arterial pressures, heart rate, and rate pressure product and lidocaine decreased the rises in arterial blood pressure and rate pressure product $(P<0.05)$. Fentanyl decreased the incidence of marked fluctuations in haemodynamic variables, often seen in geriatric patients $(P<0.05)$. The haemodynamic effects of lidocaine and fentanyl were independent of each other. Complications occurred in all groups. Lidocaine-treated patients had fewer cardiac dysrhythmias $(P<0.05)$ and 34 per cent of them had tinnitus. Fentanyl-treated patients had a higher incidence of hypotension $(P<0.05)$. Respiratory depression developed in only one per cent of the fentanyl-treated patients. Both lidocaine and fentanyl are recommended adjuncts to induction of anaesthesia with thiopentone in geriatric patients.

\section{Key words}

ANAESTHESIA: geriatric; ANAESTHETICS, INTRAVENOUS: fentanyl, lidocaine; INTUBATION, TRACHEAL: cardiovascular responses; COMPLICATIONS: hypertension, hypotension; AGE FACTORS.

From the Departments of Anaesthesia and Pharmacology and Toxicology, Queen's University, Kingston, Ontario, Canada.

Address correspondence to: Dr. Splinter, Department of Anaesthesia, Children's Hospital of Eastern Ontario, 401 Smyth Road, Ottawa, Ontario, K1H 8L1.
The sympathetic response to laryngoscopy and tracheal intubation and its pharmacological modification has been well documented in healthy patients. ${ }^{1-3}$ The geriatric patient is at particular risk of developing complications during induction of anaesthesia, because of a high incidence of symptomatic and asymptomatic cardiovascular disease. The modification of the pressor response to laryngoscopy and intubation may attenuate this response but may also result in hypotension and bradycardia after the sympathetic response has subsided.

We sought to determine (1) whether $1.5 \mathrm{mg} \cdot \mathrm{kg}^{-1}$ of lidocaine attenuates this response, (2) whether low-dose fentanyl ( 1.5 and $3 \mu \mathrm{g} \cdot \mathrm{kg}^{-1}$ ) attenuates this response, (3) whether the effects of lidocaine and fentanyl are independent of each other, and (4) whether there are complications (hypotension, cardiac dysrhythmias, and tinnitus) associated with induction of anaesthesia with thiopentone (STP) alone or in combination with lidocaine and/or low-dose fentanyl.

\section{Methods}

After ethics committee approval, 150 elective, ASA physical status I-III surgical patients of age 65 to 92 years were randomly assigned to six groups (see Tables I and II). We excluded from consideration as subjects those patients who were being treated with sympatholytic drugs, had an active seizure disorder, severe respiratory disease $\left(\mathrm{PaCO}_{2}>45 \mathrm{mmHg}\right)$, gastroesophageal reflux, or severe cardiovascular disease (Class III angina).

Baseline haemodynamic measurements

Ward baseline haemodynamic measurements are the average of the values obtained upon admission, during the next nursing shift and on the day of surgery. On arrival in the operating room the patient's heart rate (HR), systolic blood pressure (SBP), mean blood pressure (MBP), and 
TABLE I Patient characteristics and induction medications (mean \pm SEM)

\begin{tabular}{lllllll}
\hline Group & $\begin{array}{l}\text { No. of } \\
\text { patients }\end{array}$ & $\begin{array}{l}\text { Thiopentone } \\
\left(\mathrm{mg} \cdot \mathrm{kg}^{-1}\right)\end{array}$ & $\begin{array}{l}\text { Lidocaine } \\
\left(\mathrm{mg} \cdot \mathrm{kg}^{-1}\right)\end{array}$ & $\begin{array}{l}\text { Fentany } \\
\left(\mu \mathrm{g} \cdot \mathrm{kg}^{-1}\right)\end{array}$ & $\begin{array}{l}\text { Age } \\
(\mathrm{yr})\end{array}$ & $\begin{array}{l}\text { Weight } \\
(\mathrm{kg})\end{array}$ \\
\hline 1 & 31 & $3.8 \pm 0.1$ & - & - & $72 \pm 1$ & $67 \pm 3$ \\
2 & 27 & $3.5 \pm 0.2^{*}$ & 1.5 & - & $74 \pm 1$ & $66 \pm 3$ \\
3 & 25 & $2.7 \pm 0.1^{*}$ & 1.5 & 1.5 & $74 \pm 1$ & $73 \pm 3$ \\
4 & 24 & $2.3 \pm 0.2^{*}$ & 1.5 & 3.0 & $70 \pm 1 \dagger$ & $73 \pm 1$ \\
5 & 21 & $3.3 \pm 0.2^{*}$ & - & 1.5 & $73 \pm 1$ & $72 \pm 3$ \\
6 & 22 & $2.5 \pm 0.2^{*}$ & - & 3.0 & $75 \pm 1$ & $67 \pm 3$ \\
\hline
\end{tabular}

$* P<0.05$ among groups.

$\dagger \mathrm{P}<0.05$ between Group IV and Groups II, III and V].

diastolic blood pressure (DBP) were monitored with a Dinamap ${ }^{\oplus}$ automatic blood pressure cuff. The average of the first two values, which were obtained three minutes apart, represent operating room baseline values.

\section{Induction of anaesthesia}

During induction of anaesthesia the patients were breathing 100 per cent $\mathrm{O}_{2}$ by mask and the automatic blood pressure cuff cycled every minute. At the beginning of induction, patients in Groups $I I-I V$ received a bolus of lidocaine $\left(1.5 \mathrm{mg} \cdot \mathrm{kg}^{-1}\right) \mathrm{IV}$; one minute later patients in Groups III-VI received fentanyl ( 1.5 or $3 \mu \mathrm{g} \cdot \mathrm{kg}^{-1}$ ) bolus IV; and 60 seconds later all patients were given STP at the rate of $2 \mathrm{mg} \cdot \mathrm{kg}^{-1} \cdot \mathrm{min}^{-1}$ until loss of lid reflex (see Table 1). Succinylcholine $\left(1 \mathrm{mg} \cdot \mathrm{kg}^{-1}\right)$ was then administered. After relaxation, laryngoscopy and tracheal intubation were accomplished by the same anaesthetist within 15 seconds. During the induction verbal contact with the patient was maintained to assess for adverse reactions (e.g., tinnitus) to lidocaine. Anaesthesia was maintained for the next $2 \frac{1}{2}$ minutes with 70 per cent $\mathrm{N}_{2} \mathrm{O}, 30$ per cent $\mathrm{O}_{2}$ and one per cent isoflurane delivered through a coaxial circuit and controlled ventilation was established to maintain normocapnia. ${ }^{4}$ The patients' ECG (Lead II) was monitored by the attending anaesthetist for dysrhythmias and ST-T changes. Patients were not stimulated during the observation period (start of the induction to seven minutes later). At the end of the operation, patients received naloxone if their respiratory rate was less than $10 \mathrm{~min}^{-1}$ or if deemed appropriate by the attending anaesthetist.

Patients with labile haemodynamic variables were

TABLE II Patient's ASA physical status

\begin{tabular}{lrrrrrr}
\hline \multicolumn{7}{c}{ Group } \\
\cline { 2 - 7 } ASA class & \multicolumn{1}{l}{ I } & 2 & 3 & 4 & 5 & 6 \\
\hline I & 1 & 1 & 2 & 3 & 2 & - \\
II & 15 & 18 & 9 & 12 & 14 & 9 \\
III & 15 & 8 & 14 & 9 & 5 & 13 \\
\hline
\end{tabular}

identified by comparing each patient's ward baseline values with the values obtained during the observation period. Those patients whose HR, DBP, or MBP became 20 per cent greater or less than baseline values and the patients with a SBP or RPP which were not within a range of $30 \% \pm$ and $50 \% \pm$, respectively of baseline were identified.

\section{Statistical analysis}

The data were analyzed using the SAS (statistical analysis system) General Linear Model Procedure. Betweengroup analysis was done using multivariate analysis of variance, Duncan's multiple-range test and Bonferroni multiple $t$ tests. When analyzing among groups with significantly different baseline values, the baseline value became a covariate and we reanalyzed the results using analysis of variance with contrasts. The different complication rates among groups were analyzed using the Fisher Exact Test. The incidence of marked haemodynamic fluctuations among the groups was compared using chi-square analysis. All results were accepted as significant if $P<0.05$.

\section{Results}

Demographic data appear in Tables I and II. There were no significant differences for weight, sex, ASA class, anaesthetic time and laryngoscopy time. By chance the average age of patients in Group IV was significantly less than in Groups II, III and VI by Duncan's multiple-range test. This occurred because the four patients with an age $>85$ years were in Groups II, III and VI. The analysis of the effects of lidocaine and fentanyl on haemodynamic variables took into account the age difference.

\section{Barbiturate requirements}

Requirements for STP were significantly different among groups. Fentanyl, 1.5 and $3.0 \mu \mathrm{g} \cdot \mathrm{kg}^{-1}$, decreased STP requirements by 19 per cent $\left(0.7 \mathrm{mg} \cdot \mathrm{kg}^{-1}\right)$ and 35 per cent $\left(1.3 \mathrm{mg} \cdot \mathrm{kg}^{-1}\right)$ respectively and lidocaine decreased STP requirements by 13 per cent $\left(0.4 \mathrm{mg} \cdot \mathrm{kg}^{-1}\right.$ ) (see Table I). 


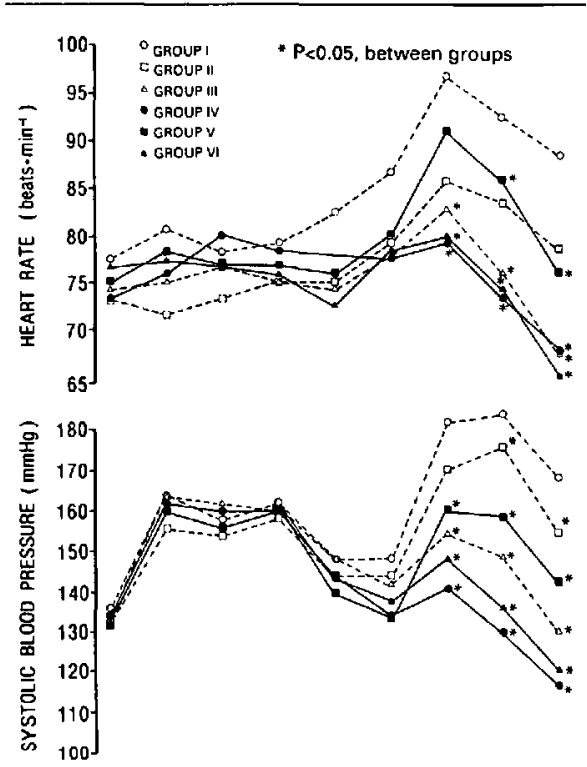

by using analysis of variance with contrasts. Lidocaine significantly attenuated DBP, MBP and RPP but its effect on heart rate was not significant, $P=0.06$.

\section{Effect of fentanyl}

Fentanyl had a marked and significant effect on all haemodynamic variables measured after intubation (Figure).

\section{Labile haemodynamic responses}

The Figure illustrates: (1) the patients receiving only STP (Group I) had a marked pressor response immediately after intubation and then their haemodynamic values returned to baseline, and (2) the fentanyl-treated patients had their immediate post-intubation pressor response attenuated, but they tended to become hypotensive several minutes after intubation. The patients with labile haemodynamic variables were identified (Table III). The fentanyl-treated patients had less haemodynamic lability $(P<0.05)$. A high incidence of stable haemodynamic variables was observed: (1) immediately after intubation if the patient received $3 \mu \mathrm{g} \cdot \mathrm{kg}^{-1}$ fentanyl (Groups IV and VI), and (2) two to three minutes after intubation if the patient was given $1.5 \mu \mathrm{g} \cdot \mathrm{kg}^{-1}$ fentanyl (Groups III and V). For example, immediately after intubation there were marked fluctuations of the RPP in 14 per cent and 65 per cent of the patients in Groups VI and I respectively. Two minutes later the patients who received $3.0 \mu \mathrm{g} \cdot \mathrm{kg}^{-1}$ of fentanyl often became hypotensive, resulting in a low incidence of stable haemodynamic variables.

\section{Complications}

The number of patients with each complication is listed in Table IV. Tinnitus occurred in 26 per cent of the patients who received lidocaine plus fentanyl and in 48 per cent of the patients who were given lidocaine only $(P=0.07)$. Three of the patients with tinnitus were noticeably distressed by the ringing in their ears. Lidocaine-treated patients had significantly fewer cardiac dysrhythmias ( $P$ $<0.05$ ).

Low-dose fentanyl increased the incidence of hypoten-

FIGURE The systolic blood pressure, heart rate and rate pressure product at rest (time $=0 ; \mathrm{WB}=$ ward baseline and $\mathrm{OR}=$ operating room baseline), during induction of anaesthesia, and before and after tracheal intubation in patients treated with thiopentone only (Group I), and in combination with lidocaine (Groups II-IV), $1.5 \mu \mathrm{g} \cdot \mathrm{kg}^{-1}$ fentanyl (Groups III \& V) and $3.0 \mu \mathrm{g} \cdot \mathrm{kg}^{-1}$ fentanyl (Groups IV and $\mathrm{VI}$ ).

\section{Effect of lidocaine}

The protective effect of lidocaine on the induction pressor response is illustrated in the Figure. Baseline (ward) heart rates were significantly different between the patients who received lidocaine and those patients that did not receive lidocaine. This chance occurrence was overcome sion during and after the observation period $(P<0.05)$. Systolic hypotension, defined as SBP less than 80 per cent of the lowest ward SBP, occurred in 35 per cent of the fentanyl-treated patients, whereas only two per cent of the no-fentanyl patients developed hypotension. This hypotensive effect was so severe in two patients that the inhalation agent concentrations were decreased during the observation period. This relative hypotension was tolerated well, with no side effects detected. Six of 34 patients with hypotension had a MBP/HR ratio of less than one, which is a risk factor for myocardial ischaemia. ${ }^{5}$ One fentanyl-treated patient had respiratory depression. 
TABLE III Frequency of labile haemodynamic variables

\begin{tabular}{|c|c|c|c|c|c|c|c|c|c|c|c|c|c|c|}
\hline \multirow[b]{3}{*}{ Value* } & \multirow[b]{3}{*}{ Timet } & \multicolumn{12}{|c|}{ Group } & \multirow{3}{*}{$\begin{array}{l}\text { Significance } \\
\text { (see \$) }\end{array}$} \\
\hline & & \multicolumn{2}{|l|}{1} & \multicolumn{2}{|l|}{2} & \multicolumn{2}{|l|}{3} & \multicolumn{2}{|l|}{4} & \multicolumn{2}{|l|}{5} & \multicolumn{2}{|l|}{6} & \\
\hline & & $L t$ & $H_{i}^{+}$ & $L$ & $H$ & $L$ & $H$ & $L$ & $H$ & $L$ & $H$ & $L$ & $H$ & \\
\hline \multirow[t]{2}{*}{ HR } & 1 & 0 & 68 & 4 & 41 & 4 & 36 & 8 & 33 & 0 & 48 & 0 & 14 & C \\
\hline & 3 & 0 & 26 & 4 & 19 & 20 & 4 & 25 & 13 & 0 & 14 & 36 & 0 & - \\
\hline \multirow[t]{2}{*}{ RPP } & 1 & 0 & 65 & 0 & 44 & 0 & 28 & 4 & 21 & 0 & 38 & 0 & 13 & C \\
\hline & 3 & 0 & 45 & 0 & 22 & 0 & 4 & 13 & 4 & 0 & 19 & 9 & 0 & $c$ \\
\hline \multirow[t]{2}{*}{ SBP } & 1 & 0 & 58 & 0 & 52 & 0 & 36 & 8 & 21 & 5 & 29 & 0 & 22 & C \\
\hline & 3 & 0 & 45 & 0 & 26 & 0 & 12 & 21 & 4 & 5 & 14 & 9 & 9 & $\mathrm{~B}$ \\
\hline \multirow[t]{2}{*}{ MBP } & 1 & 0 & 74 & 0 & 67 & 0 & 36 & 13 & 33 & 0 & 57 & 5 & 27 & $\mathrm{C}$ \\
\hline & 3 & 0 & 68 & 0 & 44 & 8 & 12 & 29 & 8 & 9 & 29 & 36 & 5 & $A, B$ \\
\hline \multirow[t]{2}{*}{ DBP } & 1 & 0 & 74 & 0 & 63 & 4 & 44 & 21 & 29 & 0 & 52 & 9 & 31 & $c$ \\
\hline & 3 & 3 & 52 & 0 & 41 & 28 & 8 & 50 & 8 & 9 & 24 & 55 & 5 & - \\
\hline
\end{tabular}

${ }^{*} \mathrm{HR}=$ heart rate $, \mathrm{min}^{-1}, \mathrm{RPP}=$ rate pressure product, $\mathrm{mmHg} \cdot \mathrm{min}^{-1}, \mathrm{SBP}=$ systolic blood pressure, $\mathrm{mmHg}, \mathrm{DBP}=$ diastolic blood pressure, $\mathrm{mmHg}, \mathrm{MBP}=$ mean blood pressure, $\mathrm{mmHg}$.

tL and $\mathrm{H}$ represent the respective percentage of patients in each group whose haemodynamic variables were lower or higher than an "acceptable" range. Those patients whose HR, DBP, or MBP became 20 per cent greater or less than ward baseline values and the patients with a SBP or RPP which were not within a range of $30 \% \pm$ and $50 \% \pm$, were identified.

$¥$ Time $=1$ represents the immediate post-intubation haemodynamic value, while time $=3$ is two minutes after time $=1$.

$\$ \mathrm{P}<0.05, \mathrm{~A}=$ the patients given lidocaine, $\mathrm{B}=$ the patients given $1.5 \mu \mathrm{g} \cdot \mathrm{kg}^{-1}$ fentanyl and $\mathrm{C}=$ the patients given $3.0 \mu \mathrm{g} \cdot \mathrm{kg}-1$ fentanyl.

Baseline haemodynamic measurements

Most investigations similar to this study determined baseline values in the operating room prior to surgery. ${ }^{6}$

Yet many anaesthetists maintain their patients at ward haemodynamic variables during anaesthesia, because these values are more representative of baseline haemodynamics variables. Ward baseline haemodynamic variables were lower than operating room baseline values except for heart rate $(P<0.05)$. The differences between SBP, MBP, DBP, and RPP were $19,19,12$, and 25 per cent respectively.

\section{Discussion}

A stable induction is a major objective in anaesthesia, especially in the geriatric patient. Each approach at

TABLE IV Complications*

\begin{tabular}{lrrrrrr}
\hline \multicolumn{9}{c}{ Group } & & & & \\
\cline { 2 - 7 } Complication & 1 & 2 & 3 & 4 & 5 & 6 \\
\hline Cardiac dysrhythmias & 6 & 1 & - & 1 & 2 & 4 \\
Respiratory depression & - & - & - & 1 & - & - \\
Tinnitus & - & 13 & 10 & 3 & - & - \\
Hypotension $\neq$ & 1 & - & 7 & 9 & 7 & 10 \\
None & 24 & 13 & 10 & 13 & 14 & 9 \\
\hline
\end{tabular}

*The number of patients in each group with a complication is listed. tGenerally VPC's; lidocaine-treated patients had fewer dysrbythmias (P<0.05, Fisher Exact Test).

fDefined as systolic blood pressure which was lower than 80 per cent of the lowest ward blood pressure. Fentanyl-treated groups had a higher incidence of hypotension $(\mathrm{P}<0.05)$. controlling the haemodynamic response to laryngoscopy and tracheal intubation has potential problems associated with it. There have been numerous pharmacological approaches but we could find only one study of geriatric patients. ${ }^{6}$ Deep anaesthesia with barbiturates or inhalational agents, ${ }^{7}$ vasodilators, ${ }^{1-3}$ beta blockers, ${ }^{8-11}$ and clonidine $^{12}$ have been used to modify the pressor response. A common approach is the use of narcotics or lidocaine.

The results of studies on the effect of lidocaine on induction haemodynamic variables have varied. ${ }^{13-20} \mathrm{Li}$ docaine alters the response to laryngoscopy and intubation by obtunding laryngeal reflexes. ${ }^{21}$ Lidocaine, which decreases MAC by 10 to 28 per cent, ${ }^{17}$ reduced STP requirements by 13.3 per cent. Haemodynamic values were significantly modified by lidocaine given $4.27 \pm$ $0.25 \mathrm{~min}$ (mean $\pm \mathrm{SD}$ ) before intubation. In younger adults the optimal time to administer IV lidocaine before intubation is approximately three minutes and lidocaine given one, two and five minutes before intubation had no beneficial effect. ${ }^{22}$ The optimal timing of injection of IV lidocaine before tracheal intubation is unknown in geriatric patients.

Complications occurred frequently among the patients given lidocaine with 34 per cent of them having tinnitus. The reported incidence of side effects from similar doses of IV lidocaine varies from 0 to 100 per cent. ${ }^{22,23}$ The dose of lidocaine associated with minimal side effects and yet clinically effective needs to be established in geriatric patients.

Low-dose fentanyl $1^{24-28}$ and other narcotics ${ }^{26-30}$ have 
been shown to attenuate the haemodynamic response to intubation. In this study both 1.5 and $3 \mu \mathrm{g} \cdot \mathrm{kg}^{-1}$ fentanyl attenuated the response to laryngoscopy and intubation in geriatric patients. The higher dose $\left(3 \mu \mathrm{g} \cdot \mathrm{kg}^{-1}\right)$ of fentanyl resulted in a more dramatic attenuation. For example, the RPP of Group VI determined immediately after intubation was $\mathbf{4 3}$ per cent less than Group I (STP only), while $1.5 \mu \mathrm{g} \cdot \mathrm{kg}^{-1}$ fentanyl (Group V) and lidocaine (Group II) decreased RPP by 30 and 14 per cent respectively. Chung et al, ${ }^{4}$ also found a beneficial effect from $3 \mu \mathrm{g} \cdot \mathrm{kg}^{-1}$ fentanyl under similar circumstances, except their geriatric patients had higher control haemodynamic values.

This study examined fluctuations of HR, SBP, MBP, DBP and RPP during the induction of anaesthesia. Other haemodynamic parameteres which can be measured include the MBP/HR ratio. ${ }^{5,31}$ The strict control of haemodynamic variables has reduced myocardial ischaemia, ${ }^{31}$ while haemodynamic aberrations, such as tachycardia, systolic bypertension and hypotension, elevated RPP and MBP/HR ratio of less than one may cause ischaemia. ${ }^{5,31-35}$ Tachycardia increases myocardial oxygen demand and decreases supply. ${ }^{34}$ Hypertension increases both demand and supply and thus has a less predictable effect on myocardial oxygen balance. RPP is correlated with myocardial oxygen demand and a threshold value of RPP had been correlated with the onset of angina. ${ }^{33.35}$ During anaesthesia myocardial ischaemia is poorly correlated with RPP. ${ }^{5}$ Buffington did not observe myocardial ischaemia if MBP exceeded HR. ${ }^{5}$ In this study, low-dose fentanyl attenuated the haemodynamic response to laryngoscopy and tracheal intubation and decreased the incidence of marked fluctuations of $H R$, BP, and RPP, while lidocaine was only observed to attenuate SBP and RPP. We did not investigate the effect of low-dose fentanyl, lidocaine and thiopentone on the ratio MBP/HR. Investigation of the effect of controlling haemodynamic parameters (HR, BP, RPP and MBP/HR) on the incidence of myocardial ischaemia in geriatric patients is indicated.

One problem with other investigations which we tried to avoid was the comparison of techniques to modify the induction haemodynamic variables without regarding the different levels of anaesthesia among the patients being studied. For example, fixing the dose of STP and using variable doses of narcotics in order to determine if the narcotics attenuate the post-intubation haemodynamic values. As we have shown, lidocaine and fentanyl decrease the requirement for STP. In addition, geriatric patients have marked differences in STP requirements. Titrating the STP to effect takes into account each patient's different anaesthetic requirements and the STPsparing effect of lidocaine and fentanyl.
In summary, $1.5 \mathrm{mg} \cdot \mathrm{kg}^{-1}$ lidocaine given approximately 4 to 4.5 minutes before intubation was beneficial because it decreased STP requirements, attenuated the pressor response to laryngoscopy and intubation and reduced the incidence of cardiac dysrhythmias. Lidocaine also has the added advantage of a short half-life. The best dose and time of injection of lidocaine before tracheal intubation in geriatric patients are unknown. Fentanyl decreased STP requirements, attenuated the response to laryngoscopy and intubation and decreased haemodynamic fluctuations during induction. Fentanyl had a greater benefit than lidocaine, but fentanyl-treated patients were at risk of hypotension several minutes after intubation. Both lidocaine and low-dose fentanyl are recommended adjuncts to induction of anaesthesia with thiopentone in geriatric patients. Further investigation is needed to examine the effects of other pharmacological approaches at controlling haemodynamic variables during the induction of anaesthesia in geriatric patients.

\section{Acknowledgements}

The authors thank their colleagues in the department of anaesthesia for their guidance and cooperation; Queen's Statlab, especially Dr. Terry Smith, for the statistical analysis; and Drs. James Morrison and Emerson Moffitt for their helpful comments.

\section{References}

1 Fassoulaki A, Kaniaris $P$. Intranasal administration of nitroglycerine attenuates the pressor response to laryngoscopy and intubation of the trachea. Br J Anaesth 1983; 55: $49-52$.

2 Stoelting $R K$. Attenuation of blood pressure response to laryngoscopy and tracheal intubation with sodium nitroprusside. Anesth Analg 1979; 58: 116-9.

3 Kamra S, Wig J, Sapru RP. Topical nitroglycerin a safeguard against pressor responses to tracheal intubation. Anaesthesia 1986; 41: 1087-91.

4 Bain JA. Spoerel WE. Prediction of arterial carbon dioxide tension during controlled ventilation with a modified Mapleson D system. Can Anaesth Soc J 1975; 22: 34-8.

5 Buffington $C W$. Hemodynamic determinants of ischemic myocardial dysfunction in the presence of coronary stenosis in dogs. Anesthesiology 1985; 63; 651-62.

6 Chung $F$, Evans $D$. Low-dose fentanyl: hacmodynamic response during induction and intubation in geriatric patients. Can Anaesth Soc J 1985; 32: 622-8.

7 Milocco I, Axsön-Lof B, William-Olsson G, Appelgren $L K$. Haemodynamic stability during anaesthesia induction and sternotorny in patients with ischaemic heart disease. A comparison of six anaesthetic techniques. Acta Anaesthesiol Scand 1985; 29: 465-73.

8 Magnusson $J$, Thulin $T$, Werner $O$, Jarhult $J$, Thomson 
$D$. Haemodynamic effects of pretreatment with metoprolol in hypertensive patients undergoing surgery. $\mathrm{Br} \mathrm{J}$ Anaesth 1986; 58: 251-60

9 Prys-Roberts C, Foex P, Biro GP, Roberts JG. Studies of anaesthesia in relation to hypertension. $\mathrm{V}$ : Adrenergic beta-receptor blockade. Br J Anaesth 1973; 45: 671-81.

10 Cucchiara RF, Benefiel DJ, Matteo RS, DeWood M, Albin $M S$. Evaluation of esmolol in controlling increases in heart rate and blood pressure during endotracheal intubation in patients undergoing carotid endarterectomy. Anesthesiology 1986; 65: 528-31.

11 Newsome LR, Roth JV, Hug CC Jr, Nagle D. Esmolol attenuates hemodynamic responses during fentanylpancuronium anesthesia for aortocoronary bypass surgery. Anesth Analg 1986; 65: 451-6.

12 Ghignone $M$, Quintin L, Duke PC, Kehler CH, Calvillo $O$. Effects of clonidine on narcotic requirements and hemodynamic responses during induction of fentanyl anaesthesia and endotracheal intubation. Anesthesiology 1986; 64: 36-42.

13 Stoeiting $R K$. Circulatory changes during direct laryngoscopy and tracheal intubation: influence of duration of laryngoscopy with or without prior lidocaine. Anesthesiology 1977; 47: 381-4.

14 Stoelting $R K$. Blood pressure and heart rate changes during short-duration laryngoscopy for tracheal intubation: influence of viscous or intravenous lidocaine. Anesth Analg 1978; 57: 197-9.

15 Abou-Madi MN, Keszler H, Yacoub JM. Cardiovascular reactions to laryngoscopy and tracheal intubation following small and large intravenous doses of lidocaine. Can Anaesth Soc J 1977; 24: 12-9.

16 Hamill JF, Bedford RF, Weaver DC, Colohan AR. Lidocaine before endotracheal intubation: intravenous or laryngotracheal? Anesthesiology $1981 ; 55: 578-81$.

17 Himes RS, Difazio CA, Burney RG. Effect of lidocaine on the anesthetic requirements for nitrous oxide and halothane. Anesthesiology 1977; 47: 437-40.

18 Kasten $G W$, Owens $E$. Evaluation of lidocaine as an adjunct to fentanyl anaesthesia for coronary artery bypass graft surgery. Anesth Analg 1986; 65: 511-5.

19 Chraemmer-Jprgensen B, Høilund-Carlsen PF, Marving J, Christensen $V$. Lack of effect of intravenous lidocaine on hemodynamic responses to rapid sequence induction of general anesthesia. A double-blind controlled clinical trial. Anesth Analg 1986; 65: 1037-41.

20 Derbyshire DR, Smith G, Achola KJ. Effect of topical lignocaine on the sympathoadrenal responses to tracheal intubation. Br J Anaesth 1987; 59: 300-4.

21 Badrinath SK, Vazeery A, McCarthy RJ, Ivankovich $A$. The effect of different methods of inducing anesthesia on intraocular pressure. Anesthesiology 1986; 65: $431-5$.
22 Tam $S$, Chung $F$, Campbell $M$. Intravenous lidocaine: optimal time of injection before tracheal intubation. Anesth Analg 1987; 66: 1036-8.

23 Haasio J, Hekali $R$, Rosenberg PH. Influence of premedication on lignocaine-induced acute toxicity and plasma concentrations of lignocaine. Br J Anaesth 1988; 61: $131-4$.

24 Dahlgren N, Messeter $K$. Treatment of stress response to laryngoscopy and intubation with fentanyl. Anaesthesia 1981; 36: 1022-6.

25 Martin DE, Rosenburg $H$, Aukbury $S J$ et al. Low-dose fentanyl blunts circulatory responses to tracheal intubation. Anesth Analg 1982; 61: 680-4.

26 Black TE, Kay B, Healy TEJ. Reducing the haemodynamic responses to laryngoscopy and intubation. A comparison of alfentanil with fentanyl. Anaesthesia 1982; 39: 883-7.

27 Hynynen $M$, Korttilea $K$, Wirtavuori $K$, Lehtinen A-M. Comparison of alfentanil and fentanyl as supplements to induction of anaesthesia with thiopentone. Acta Anaesthesiol Scand 1985; 29: 168-74.

28 Kay B, Healy TEJ, Bolder PM. Blocking the circulatory responses to tracheal intubation. A comparison of fentanyl and nalbuphine. Anaesthesia 1985; 40: 960-3.

29 Kay B, Nolan D, Mayall $R$, Healy TEJ. The effect of sufentanil on the cardiovascular responses to tracheal intubation. Anaesthesia 1987; 42: 382-6.

30 Morton NS, Hamilton WF. Alfentanil in an anaesthetic technique for penetrating eye injuries. Anaesthesia 1986; 41: 1148-51.

31 Montejo LS, Coriat $P$, Godet $G$, Baron JF, Viars $P$. Hemodynamic predictors of myocardial ischemia in patients undergoing aortic vascular surgery: at last we can measure them! Anesthesiology 1988; 69: A279.

32 Goehner $P$, Hollenberg $M$, Leung $J$ et al. Hemodynamic control suppresses myocardial ischemia during isoflurane or sufentanil anesthesia for CABG. Anesthesiology 1988; 69: A32.

33 Robinson $B F$. Relation of heart rate and systolic blood pressure to the onset of pain in angina pectoris. Circulation 1967; 35: 1073-83.

34 Hoffman JI. Transmural myocardial perfusion. Prog Cardiovasc Dis 1987; 29: 429-64.

35 Rooke GA, Feigel EO. Work as a correlate of canine left ventricular oxygen consumption, and the problem of catecholamine oxygen wasting. Circ Res 1982; 50: 27386.

\section{Résumé}

Nous avons mesuré les conséquences hémodynamiques de la laryngoscopie et de l' intubation chez 150 patients de plus de 64 ans qui avaient eu une induction de leur anesthésie avec du thiopental seul ou en combinaison avec $1.5 \mathrm{mg} \cdot \mathrm{kg}^{-1}$ de 
Lidocaine etlou 1.5 ou $3.0 \mu \mathrm{g} \cdot \mathrm{kg}^{-1}$ de fentanyl. Le fentanyl anténua l'augmentation des pressions artérielles systolique, diastolique et moyenne, du pouls et du produit pouls-pression alors que la lidocaïne fit de même avec la pression artérielle et le produit pouls-pression $(P<0.05)$. En plus, les fluctuations hémodynamiques fréquentes chez les patients agés, furent moins marquées avec le fentanyl $(P<0.05)$. Par ailleurs la lidocaïne et le fentanyl agissaient indépendamment l'un de lautre. Il y eu des complications dans tous les groupes: entre autres, 34 pour cent de tinnitus mais moins de dysrythmies pour la lidocaine $(P<0.05)$ et plus d' hypotension pour le fentanyl $(P$ $<0.05)$ qui ne déprima la respiration que dans un seul cas. La lidocaïne et le fentanyl peuvent donc être recommandès à titre de complément à l' induction de l'anesthésie au thiopental chez les patients agés. 